\title{
Effect of Lingonberry Extracts on Blood Pressure and Myocardium in Paracetamol Intoxication
}

\author{
Ioana ROMAN ${ }^{1 *}$, Anca FARCAȘ ${ }^{2,3}$, Vlad Al. TOMA ${ }^{2,3}$
}

${ }^{1}$ Institute of Biological Research Cluj-Napoca, Branch of N. I.R.D.B.S., Bucharest, 48 Republicii Str., 400015, Cluj-Napoca, Romania

${ }^{2}$ National Institute for Research and Development of Isotopic and Molecular Technologies, 67-103

Donat, 400293, Cluj-Napoca, Romania

3 "Babes-Bolyai" University, $1^{\text {st }}$ Mihail Kogalniceanu Str., 400084, Cluj-Napoca, Romania

*corresponding author: ioana.roman@icbcluj.ro

Bulletin UASVM Veterinary Medicine 74(1) / 2017,

Print ISSN 1843-5270; Electronic ISSN 1843-5378

DOI:10.15835/buasvmcn-vm: 12626

\begin{abstract}
In this study we tried to see how (1:1 and 3:1) lingonberry extract act as protective agents of the myocardium and blood pressure in toxicosis induced by paracetamol in rats. Experiments were made on white female Wistar rats, weighing $135 \pm 20 \mathrm{~g}$ which were divided into 6 groups of 7 animals each: control group (C); Paracetamol treated group (P) - $75 \mathrm{mg}$ acetaminophen/100 g bw for 10 days. 1:1 lingonberry hidroalcoholic treated group (Lha), (200 $\mathrm{mg} / 100 \mathrm{~g}$ bw ( $80 \mu \mathrm{g}$ benzoic acid/100 g bw) for 15 days. 3:1 lingonberry dried extract group (Ld), $100 \mathrm{mg} / 100$ $\mathrm{g}$ bw (112 $\mu \mathrm{g}$ benzoic acid/100 g bw), for 15 days. P+Lha (PLha) and P + Ld (PLd) treated group. Blood pressure increases following administration of paracetamol and decreases under treatment with lingonberry extract, more obvious to 3: 1 lingonberry dried extract. Administration of Paracetamol, lingonberry extracts used simple or in combination with Paracetamol does not affect the myocardium histological structure. Histoenzimological there is a slight decrease of SDH activity in the groups P and PLd and an increase in Lha group. CyOx activity is increased in Lha and Ld group. The dried lingonberry extract has no apparent action on the myocardium instead has antihypertensive properties more obvious than the lingonberry alcoholic extract.
\end{abstract}

Keywords: blood pressure, lingonberry extract, myocardium, Paracetamol, rats.

\section{INTRODUCTION}

High blood pressure is a common problem with high frequency around the world. Cardiovascular risk factors, such as hypertension, arterial stiffness, hypercholesterolemia, insulin resistance and metabolic syndrome often coexist leading to increased cardiovascular morbidity and health problems (Krousel-Wood et al., 2004). On the other hand Paracetamol is an analgesic which primarily is hepatotoxic and not at least nephrotoxic. It is sold in many forms, either alone or in combination with other analgesia such as codeine or ibuprofen, and as branded preparations for colds and flu, migraine and menstrual discomfort. It is assumed that paracetamol, like the non-steroidal antiinflammatory drugs (NSAIDs), acts through the cyclo- oxygenase (COX) pathway, reducing the production of biologically active prostanoids (PGs), such as PGE2, which mediate inflammation and pain. Osteoarthritis (OA) and hypertension are common conditions, increasing in prevalence with age and often co-existing in the same patient. It was proved that both NSAIDs and selective COX-2 inhibitors increase BP in hypertensive and normotensive individuals, interfere with antihypertensive treatment (Pope et al., 1993; Johnston et al., 1994; Aw et al., 2005) and increase the risk of serious cardiovascular events 
(Schjerning et al., 2011, Trelle et al., 2011). As a result, intoxication with paracetamol can be used as a model to study the induction of hypertension in experimental animal models.

Natural products from plant are a rich source used for centuries to cure various diseases. The use of bioactive compounds from plants is growing because it was found that allopathic synthetic drugs cause side effects that often are more dangerous than the disease. Instead, drugs derived from plants are based on the premise that they contain natural substances that can promote health and improve disease (Kamboj, 2000; Ramchoun et al., 2009; Sen et al., 2009). Thus, as alternative treatment, polyphenols have been suggested to have protective effects against cardiovascular diseases (Stoclet et al., 2004). Berries are rich in polyphenols. In Romania, among other berries we also meet lingonberries. Lingonberry (Vaccinium vitis-idaea L.) is a small, evergreen wild shrub, with edible red berries. In Romanian flora, the Ericacee are represented by 14 species of dwarf shrubs and subshrubs, spread in the mountainous area where it forms characteristic associations (Anghel et al., 1965; Ghişa et al., 1970). The fruits contain anthocyanins, giving the red color at maturity of these fruits (Li et al. 2011). They also contain proantocians, organic acids, flavonoids, vitamins and mineral salts (Ciulei et al., 1993; Istudor, 1998).

Aims: To emphasize how lingonberry extracts (1:1 and 3:1) act as protective agents of the myocardium and blood pressure against paracetamol induced toxicosis in rats.

\section{MATERIALS AND METHODS}

Experiments were performed on white female Wistar rats*, weighing $135 \pm 20$ g, divided into 6 groups of 7 animals each: control group (C); Paracetamol intoxicated group, $75 \mathrm{mg} / 100 \mathrm{~g}$ bw (P); lingonberry dry extract treated group (Ld) (100 mg extract/100 g bw); lingonberry hidroalcoholic extract treated group (Lha) (200 mg extract/100 g bw); P + Ld treated group (PLd) and $\mathrm{P}+$ Lha treated group (PLha). Plant extracts were administered by gavage, á jeun, for a period of 15 days.

The lingonberry fruit extract was obtained from fresh fruit harvested at Băişorii Mount (Cluj county) at the end of August 2014 at the UMF "Iuliu Hațieganu" Cluj-Napoca. It was obtained $500 \mathrm{ml}$ of a hydroalcoholic extract of $45^{\circ}$ respectively an extract of $1: 1$, which means that $1 \mathrm{ml}$ of extract corresponds to $1 \mathrm{~g}$ of fresh fruit (content of benzoic acid was 40mg / 100g) and the dried extract was obtained from the fluid 1:1 extract in an installation of fluid bed into the Aeromatic-Strea-1 (Gea-Switzerland) apparatus, by the adsorption of the fluid extract on a mixture of microcrystalline cellulose-lactose $(2: 1)$, so that $1 \mathrm{~g}$ of the dry extract corresponds to $3 \mathrm{~g}$ of $1: 1$ fluid extract (or $1 \mathrm{~g}$ of fresh fruits), that we finally obtained a dry extract 3: 1 (content of benzoic acid was $112 \mathrm{mg} / 100 \mathrm{~g}$ ). Qualitative analysis of the polyphenolic compounds of the lingonberry extracts was done by thin-layer chromatography (TLC), spectrofotometry and high performance liquid chromatography (HPLC).

Blood pressure monitoring was performed within 0-7-14 days (Vital functions monitor for laboratory animals - CODA Non-Invasive Blood Pressure System)

In the $16^{\text {th }}$ day, animals were killed by decapitation after previous anesthesia with ketamine - xylazine cocktail (60:7.5 mg). Myocardium was harvested for hisological and histo-enzymological study with the usual methods ( Mureșan et al., 1974).

Animals were obtained from the biobasis of „Iuliu Hatieganu” MPU, Cluj-Napoca and kept under standardized zoohigienical conditions according to the Law no.43/2014 on the protection of animals used for scientific purposes and to the 2010/63/UE Directive with the approval of the Ethics Committee from the Institute of Biological Research, Cluj-Napoca, Romania.

\section{RESULTS AND DISCUSSION}

Besides the analgesic, anti-pyretic and antiinflammatory effects, acetaminophen known as paracetamol may also interfere with the blood pressure regulation. As noted by Curhan et al. (2002) acetaminophen was significantly associated with a high risk of hypertension. In order to increase the blood pressure, analgesic drugs, such as paracetamol can act through different mechanisms starting with the alteration of prostaglandins production, degreasing the renal ions excresion and NO inhibition (Amin et al., 1999).

At weekly intervals, we found that BP values tend to decrease in the treated groups with 


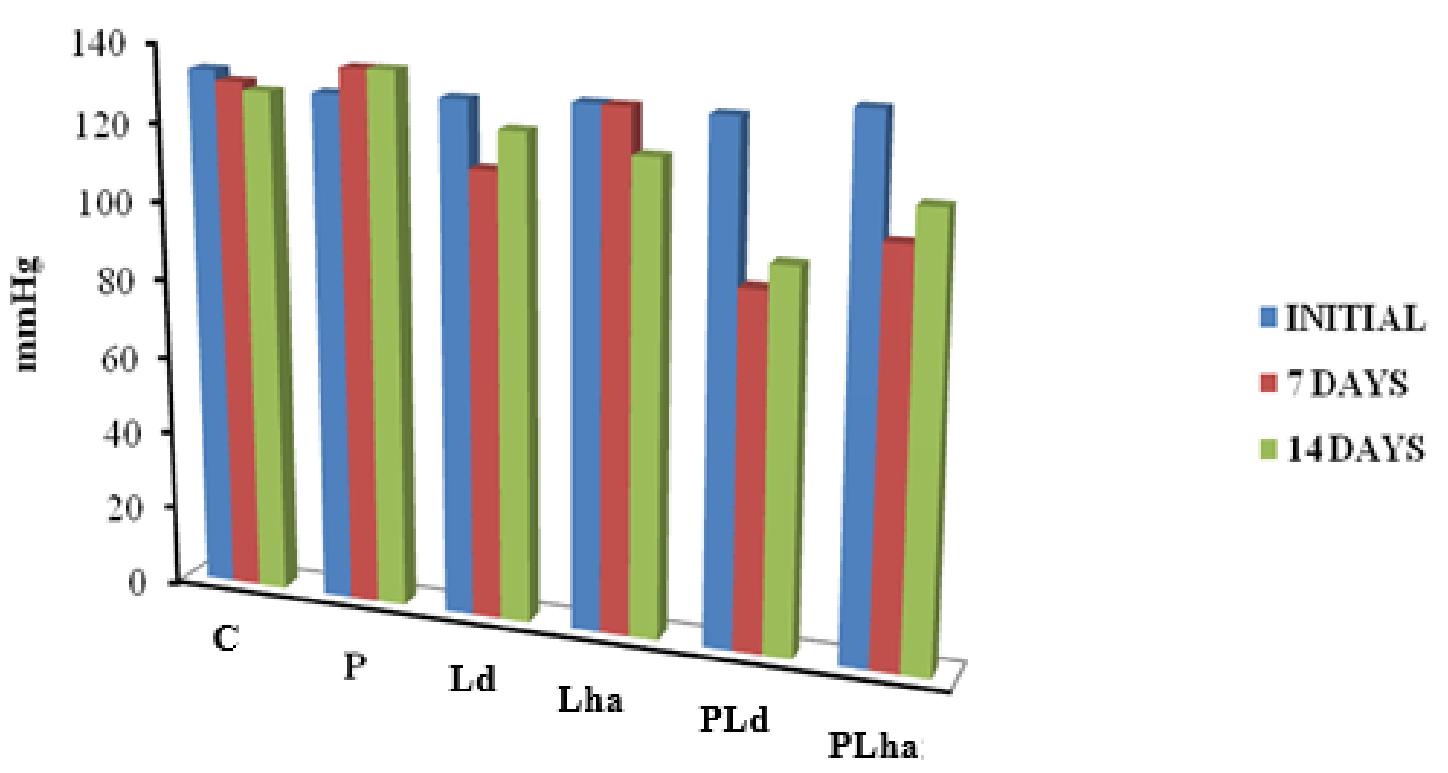

Fig. 1. Blood pressure dynamics $(0,7,14$ days $)$ in 6 experimental groups.

lingonberry extract including the one treated with paracetamol and lingonberry extract. However, there was a decrease of BP values in those receiving dry lingonberry extract and dry lingonberry extract combined with paracetamol.

In the paracetamol treated group is a slight increase of BP compared to control group at measurements 2 and 3 (Fig. 1).

Cardiovascular diseases as well as many diseases involving vascular integrity, are growing among the world population (Krousel-Wood et al., 2004). The main treatments for hypertension consist in the administration of antihypertensive, eg, diuretics, beta-blockers, angiotensin converting enzyme inhibitors, type I angiotensin receptor antagonists and calcium antagonists (Mancia et al., 2007). Lately, it was suggested that polyphenols have protective effects against cardiovascular diseases (Stoclet et al., 2004).

Lingonberry is a forest fruit rich in polyphenols and vitamines C and E (Sudano et al., 2012). Polyphenols, particularly the flavonoids inhibit the atherosclerosis development in animal models. Also, favonols improve the endothelial function, reduce blood pressure and inhibit platelet reactivity (Grassi et al., 2009, Heiss et al., 2010).

In Kivimäki and coauthors' previous study it is shown that lingonberry juice enhanced endothelium-dependent vascular relaxation in spontaneously hypertensive rats (SHR) (Kivimäki et al., 2011). It is suggested that blood pressure - lowering effect of polyphenol-rich foods is partly due to inhibition of angiotensin-converting enzyme (ACE), which is a key regulator of blood pressure (Actis-Goretta et al., 2006; Persson et al., 2011). Vascular endothelium has an important role in the regulation of blood pressure and vascular function by controlling vascular tone. Endothelium maintains the balance between vasoconstriction and vasodilatation synthesizing and releasing various relaxing factors, like nitric oxide (NO), cyclo-oxygenase (COX) - derived prostanoids and endothelium-derived hyperpolarizing factor (EDHF) (Félétou and Vanhoutte, 2006; Vapaatalo and Mervaala, 2001). In large arteries, NO is the most important vasorelaxing factor (Shimokawa and Tsutsui, 2010; Shimokawa et al., 1996).

Histologically, the myocardium is weakly influenced by acetaminophen intoxication. Overall, extracts administration seems to stimulate myocardial mitochondrial activity (Lha $>$ Ld), but this should be deepened in order to elucidate the mechanisms involved. It seems that lingonberry extracts are devoided of action on the myocardium. In the intoxicated groups with paracetamol and then treated either with hydroalcoholic or dried lingonberry extract there is emphasized a functional-structural reactivity, depending on the extract nature. Myocardium is normal both in PLha and the PLd group, suggesting a beneficial effect of these extracts on cardiac muscle fiber - 
Tab. 1. Semiquantitative histoenzimological evaluation of the kidney and myocardium (after Barka international units system).

\begin{tabular}{ccc}
\hline & \multicolumn{2}{c}{ MYOCARD } \\
\cline { 2 - 3 } & CyOx & SDH \\
\hline C & 3 & 3 \\
\hline P & 2 & 2,5 \\
\hline Lha & 4 & 4 \\
\hline Ld & 3 & 3 \\
\hline PLha & 3 & 4 \\
\hline PLd & 3 & 3 \\
\hline Note: (0-lack of enzyme activity, 1- weak reaction, 2-moderate reaction, 3- medium reaction,
\end{tabular}

4 -intense reaction, 5- very intense reaction).

myocardium has not suffer emphasized changes in the case of acetaminophen intoxication, reason for which there is no significant regeneration in action of Vaccinium vitis-idaea extracts.

The histoenzimological study of myocard shows a normal appearance as concern the CyOx and SDH activity in the group C. There is a stronger reaction of $\mathrm{SDH}$ compared to $\mathrm{CyOx}$. In group $\mathrm{P}$ there is a significant decrease in mitochondrial activity of these two enzymes in the heart muscle fibers. Lingonberry extracts (Lha and Ld group) administration does not influence the myocardial $\mathrm{SDH}$ and CyOx activity, the structures having a normal aspect. Concomitant administration of paracetamol and Lha extract (group PLha) have a positive influence on myocardial mitochondrial activity, leading to the significant increases of SDH activity and then of CyOx. In PLd group is an increase of a lower intensity of myocardial enzyme activity compared to the group PLha. (Tab. 1)

Following histological, histoenzimological and in fluorescence analysis can be seen that the paracetamol has less adverse effect on the myocardium. Extracts administration does notlead to changes of the pathological nature. However, the combination of extracts (hydroalcoholic and dried lingonberry extract) with sub-chronic administration in toxic dose of paracetamol reveals different protective effects, depending on the extract nature.

The studied lingonberry extracts fall into two quite different matrices. The liquid extract is a hydro-alcoholic extract, where we find the waterinsoluble compounds such as benzoic acid or a series of antioxidant compounds. Dried extract, resuspended in water, has a lower biochemical diversity. Extracts administration of does not induce pathological changes such as histology and fluorescent aspects. We obtained comparable results in similar experiments in which we induced alcohol intoxication (Roman et al., 2014).

\section{CONCLUSION}

The dried lingonberry extract has no apparent action on the myocardium instead has antihypertensive properties more obvious than the lingonberry alcoholic extract.

Acknowledgements: This article is based on work supported by the ANCS under grant number PN 16 19/2016 (BIODIVERS) to National Institute of Research and Development for Biological Sciences (NIRDBS), Bucuresti, Romania.

\section{REFERENCES}

1. Actis-Goretta L, Ottaviani JI, Fraga CG (2006). Inhibition of angiotensin converting enzyme activity by flavanol-rich foods. J Agric Food Chem 54: 229-234.

2. Amin AR, Attur MG, Pillinger M, Abramson SB (1999). The pleiotropic functions of aspirin: mechanism of action, Cell Mol Life Sci 56:305-312.

3. Anghel Gh, Niedermaier K, Burcea P, Stângă N, Șerbănescu I (1965). Studiul și cartarea pășunilor din corpul CrințMunţii Cibinului, S.S.N.G. Comunicări de Bot. 3: 47-80.

4. Aw T, Haas S, Liew D, Krum H (2005). Meta-analysis of cyclooxygenase-2 inhibitors and their effects on blood pressure. Arch Intern Med 165: 490-96.

5. Ciulei I, Grigorescu E, Stănescu U (1993). Plante medicinale, Fitochimie, Fitoterapie. Vol.I. Edit. Medicală, București, $732 \mathrm{p}$.

6. Curhan G, Willett WC, Rosner B, Stampfer MJ (2002). Frequency of analgesic use and risk of hypertension in younger women, Arch Intern Med 162: 2204-2208.

7. Félétou M, Vanhoutte PM (2006). Endothelial dysfunction: a multifaceted disorder (The Wiggers Award Lecture) 
american journal of physiology. Heart Circ Physiol 291: 985-1002.

8. Ghişa E, Răsmeriţă I, Spârchez Z (1970). Contribuţii la studiul calunetelor din M-ţii Apuseni. Contribuţii Botanice (Cluj): 183-190.

9. Grassi D, Desideri G, Croce G, Tiberti S, Aggio A (2009). Ferri C Flavonoids, vascular funtion and cardiovascular protection. Curr Pharm Des 15: 1072-1084.

10. Heiss C, Keen CL, Kelm M (2010). Flavanols and cardiovascular disease prevention. Eur Heart J: 31, 25832592.

11. Istudor V (1998). Farmacognozie, Fitochimie, Fitoterapie. Vol.I. Edit.Medicală, Bucureşti, 399 p.

12. Johnston A, Nguyen M, Day R (1994). Do nonsteroidal anti-inflammatory drugs affect blood pressure? A metaanalysis. Ann Intern Med 121: 289-300.

13. Kamboj VP (2000). Herbal medicine. Curr Sci 78: 35-39.

14. Kivimäki AS, Ehlers PI, Turpeinen AM, Vapaatalo H, Korpela R (2011). Lingonberry juice improves endotheliumdependent vasodilatation of mesenteric arteries in spontaneously hypertensive rats in a long-term intervention. J Funct Foods 3: 267-274.

15. Krousel-Wood MA, Muntner P, He J, Whelton PK (2004). Primary prevention of essential hypertension. Med Clin North Am 88: 223-238.

16. Li R, Wang P, Guo Q-Q, Wang Z-Y (2011). Anthocyanin composition and content of the Vaccinium uliginosum berry. Food Chem 125: 116-120.

17. Mancia G, Laurent S, Agabiti-Rosei E, Ambrosioni E, Burnier M, Caulfield MJ (2007). Guidelines for the management of arterial hypertension: the task force for the management of arterial hypertension of the european society of hypertension (ESH) and of the european society of cardiology (ESC). Eur Heart J 28: 1462-1536.

18. Mureşan E, Gaboreanu M, Bogdan AD, Baba AI (1974). Tehnici de histochimie normală şi patologică. Ed. Ceres, București, 482 p.

19. Persson IA, Persson K, Hägg S, Andersson RG (2011). Effects of cocoa extract and dark chocolate on angiotensinconverting enzyme and nitric oxide in human endothelial cells and healthy volunteers - a nutrigenomics perspective. J Cardiovasc Pharmacol 57: 44-50.

20. Pope J, Anderson J, Felson D (1993). A meta-analysis of the effects of nonsteroidal anti-inflammatory drugs on blood pressure. Arch Intern Med 153: 477-484.
21. Ramchoun M, Harnafi H, Alem C, Benlys M, Elrhaffari L, Amrani S (2009). Study on antioxidant and hypolipedimic effects of polyphenol rich extract from Thymus vulgaris and Lavendula Multifida. Pharmacognsy Res 1: 106-112.

22. Roman I, Puică C, Toma AV (2014). The effect of Vaccinium vitis idaea $\mathrm{L}$. extract administration on kidney structure and function in alcohol intoxicated rats. Studia Univ. VG, SSV 24(4): 363-367.

23. Schjerning Olsen AM, Fosbøl EL, Lindhardsen J, Folke F, Charlot M, Selmer C, Lamberts M, Bjerring Olesen J, Køber L, Hansen PR, Torp-Pedersen C, Gislason GH (2011). Duration of treatment with nonsteroidal antiinflammatory drugs and impact on risk of death and recurrent myocardial infarction in patients with prior myocardial infarction: a nationwide cohort study. Circulation 123: 2226-2235.

24. Sen S, Chakraborty R, De B, Mazumder J (2009). Plants and phytochemicals for peptic ulcer: an overview. Pharmacognosy Rev. 3: 270-279.

25. Shimokawa H, Tsutsui M (2010). Nitric oxide synthases in the pathogenesis of cardiovascular disease Lessons from genetically modified mice. Pflugers Archiv: European Journal of Physiology 45: 959-967.

26. Shimokawa H, Yasutake H, Fujii K, Owada MK, Nakaike R, Fukumoto Y, Takayanagi T, Nagao T, Egashira K, Fujishima M, Takeshita A (1996). The importance of the hyperpolarizing mechanism increases as the vessel size decreases in endothelium-dependent relaxations in rat mesenteric circulation. J Cardiovasc Pharmacol 28: 703711.

27. Stoclet JC, Chataigneau T, Ndiaye M, Oak MH, El Bedoui J, Chataigneau M, Schini-Kerth VB (2004). Vascular protection by dietary polyphenols. Eur J Pharmacol 500: 299-313.

28. Sudano I, Flammer AJ, Periat D, Enseleit F, Hermann M, Wolfrum M, Hirt A, Kaiser P, Hurlimann D, Neidhart M, Gay S, Holzmeister J, Nussberger J, Mocharla P, Landmesser U, Haile S, Corti R, Vanhoutte PM, Luscher TF, Noll G, Ruschitzka F (2010). Acetaminophen increases blood pressure in patients with coronary artery disease. Circulation 122: 1789-1796.

29. Trelle S, Reichenbach S,Wandel S, Hildebrand P, Tschannen B, Villiger PM, Egger M, Juni P (2011). Cardiovascular safety of non-steroidal anti-inflammatory drugs: network analysis. BMJ 342: c7086.

30. Vapaatalo H, Mervaala E (2001). Clinically important factors influencing endothelial function. Med Sci Monit 7: 1075-1085. 